\title{
Pengaruh Locus of Control dan Perceived Organizational Support pada Organizational Citizenship Behavior Guru SMA Negeri di Kotamadya Sukabumi
}

\author{
Dade Nurfalah \\ Pendidikan Matematika, STKIP Kusuma Negara, Indonesia \\ dadonur@gmail.com
}

\begin{abstract}
Abstrak
Penelitian ini membahas tentang pengaruh locus of control (LOC), dan perceived organizational support (POS) terhadap organizational citizenship behavior (OCB) Guru SMA Negeri di Kota Sukabumi, ini diltarbelakangi oleh pentingnya OCB guru, karena disamping seorang guru harus melaksanakan tugas pokoknya (in-role performance) sebagai guru, disamping itu guru harus mempunyai perilaku sukarla (extra-role performance) di luar tanggung jawabnya melaksanakan tugas utamanya. Tujuan penelitian ini adalah untuk mengetahui pengaruh langsung; positif (1) LOC terhadap OCB guru, (2) POS terhadap OCB guru, dan (3) LOC terhadap POS. Dalam rancangan penelitian ini menggunakan pendekatan kuantitatif dan menggunakan metode survei dengan analisis jalur yang diterapkan dalam pengujian hipotesis. Populasi target dalam penelitian ini adalah semua guru di SMA Negeri Kota Sukabumi, sebanyak 70 orang guru sebagai sampel dari populasi sebanyak 85 guru, dengan menggunakan rumus Slovin. Hasil penelitian ini adalah (1) terdapat pengaruh langsung positif LOC terhadap OCB, dengan nilai koefisien jalur sebesar 0,259. (2) terdapat pengaruh langsung positif POS terhadap OCB, dengan nilai koefisien jalur sebesar 0,340 . (3) terdapat pengaruh langsung positif LOC terhadap POS, dengan nilai koefisien jalur sebesar 0.361 . Hal ini memberikan makna bahwa untuk meningkatkan OCB guru di SMA Negeri kota Sukabumi dapat dicapai melalui peningkatan LOC, dan POS
\end{abstract}

Kata kunci: locus of control, organizational citizenship behaviors, perceived organizational support.

Dikirim: 24 November 2020

Direvisi: 05 Januari 2021

Diterima: 07 Januari 2021

\section{Identitas Artikel:}

Nurfalah, D. (2021). Pengaruh Locus of Control, dan Perceived Organizational Support pada Organizational Citizenship Behavior Guru SMA Negeri di Kotamadya Sukabumi. Jurnal Ilmu Pendidikan (JIP) STKIP Kusuma Negara, 12(2), 156-164.

\section{PENDAHULUAN}

Sumber daya manusia merupakan aset penting dalam suatu organisasi, karena merupakan sumber yang mengendalikan organisasi serta mempertahankan dan mengembangkan organisasi dalam menghadapi berbagai tuntutan zaman. Oleh karena itu sumber daya manusia harus diperhatikan, dijaga, dan dikembangkan. Demikian halnya dengan institusi pendidikan, harus memperhatikan, menjaga, dan mengembangkan sumber daya manusianya, khususnya para guru. Sumber daya manusia perlu dikembangkan secara terus menerus agar diperoleh sumber daya manusia yang bermutu dalam artian sebenarnya yaitu pekerjaan yang dilaksanakan akan menghasilkan sesuatu yang dikehendaki.

Sekolah sebagai salah satu lembaga pendidikan yang diharapkan mampu menghasilkan sumber daya berkualitas, perlu didukung oleh guru yang 
berdedikasi tinggi, kreatif dan inovatif, sehingga dapat berjalan dengan baik sesuai dengan sistem dan norma yang berlaku. Ketersediaan guru yang berkualitas, akan membawa sekolah mencapai tujuan yang telah ditetapkan. Guru adalah salah satu faktor penentu bagi keberhasilan pendidikan di sekolah, karena guru merupakan salah satu sumber pembelajaran yang sangat berarti bagi peserta didik. Di tangan gurulah hasil pembelajaran lebih banyak ditentukan, yaitu pembelajaran yang berkualitas sekaligus bermakna sebagai pemberdaya kemampuan dan kesanggupan peserta didik.

Guru merupakan profesi atau pekerjaan yang memerlukan keahlian khusus atau profesionalisme guru. Arti dari profesional adalah sebuah profesi yang tidak dapat dilakukan oleh sembarangan orang (Usman, 2012). Selanjutnya Kunandar (2007) menjelaskan bahwa, profesionalisme adalah kebutuhan yang tidak dapat tunda lagi, semakin meningkatnya persaingan yang semakin ketat dalam era globalisasi maka perlu di tingkatkan lagi profesionalisme dari seorang guru. Profesional merupakan pekerjaan atau kegiatan yang dilakukan oleh seseorang dan menjadi sumber penghasilan kehidupan yang memerlukan keahlian atau kecakapan yang memenuhi mutu atau norma tertentu serta memerlukan pendidikan profesi.

Guru dan pendidik memainkan peran penting dalam mendukung dan memotivasi peserta didik. Dikarenakan, tujuan utama dari pembelajaran adalah untuk mempersiapkan peserta didik menjadi pekerja yang sukses di dunia kerja (Finch \& Crunkilton, 1999). Profesionalisme guru mewujudkan dirinya paling tidak dalam dua hal, yaitu: Pertama, praktik pengajaran menunjukan pengaruh keahlian. Kedua, guru berkomitmen terhadap kesuksesan peserta didiknya. Tujuan pengajaran mendorong guru untuk bekerja melampaui persyaratan minimal yang dispesifikasikan oleh tugas-tugas di kelas. Guru profesional juga mampu melakukan pengarahan diri yang didasarkan pada pengetahuan dan komitmen guru terhadap peserta didik. Sifat dasar perilaku guru profesional adalah melakukan tindakan-tindakan di luar tugas resminya.

Dalam konteks perilaku keorganisasian, persoalan yang umumnya dihadapi institusi pendidikan dan guru berkaitan dengan salah satu dari tiga perilaku penting dari seorang pegawai dalam sebuah organisasi, yaitu perilaku extra-role atau perilaku baik warga organisasi yang populer sebagai OCB. Pegawai yang menampilkan perilaku OCB disebut sebagai pegawai yang baik (good citizen). Pada tingkat persaingan jasa pendidikan yang tinggi sekarang ini, agar tetap menarik minat dan loyalitas peserta didik dalam menggunakan jasa pendidikan di institusi pendidikan tertentu, dalam operasionalnya dibutuhkan adanya perilaku extra-role dari seluruh tenaga pendidik khususnya yang terlibat dalam pelayanan jasa pendidikan.

Fenomena yang terjadi tentang OCB guru di SMA Negeri Kota Sukabumi mengalami penurunan, dengan diindikasikan; (1) perilaku guru dalam bekerja kurang memiliki rasa kerjasama dengan rekan kerja (2) ketelitian dalam bekerja masih rendah, dan (3) sikap sportif dalam bekerja masih kurang. Pengamatan prasurvei yang dilakukan pada guru di SMA Negeri Kota Sukabumi, masih terlihat adanya tindakan-tindakan indisipliner yang dilakukan sebagian kecil guru, diantaranya terdapat guru yang terlambat masuk jam kerja dan absensi tidak ditanda tangani. Masih adanya sikap tidak disiplin dan kooperatif guru terhadap peraturan sekolah, di mana sikap disiplin dan kooperatif merupakan indikasi 
terciptanya OCB yang mewakili dimensi Conscientiousnes. Dari semua permasalahan di atas menunjukan betapa pentingnya permasalahan OCB untuk diteliti, dan prediktor apa yang dapat mempengaruhi peningkatan dari rendahnya OCB guru di SMA Negeri Kota Sukabumi.

Penelitian ini menganalisis pengaruh langsung LOC, dan POS terhadap OCB, dan pengaruh langsung LOC terhadap POS, dengan subjek penelitian adalah Guru Sekolah Menengah Atas Negeri di Kota Sukabumi.

\section{Organizational Citizenship Behavior (OCB)}

George, Jones \& Sharbrough (2005) mendefinisikan OCB sebagai perilaku yang melebihi panggilan tugas dimana merupakan perilaku yang tidak ditentukan oleh anggota organisasi tetapi meskipun demikian penting bagi kelangsungan hidup dan efektifitas organisasi. Sebagai contoh OCB meliputi membantu rekan kerja, melindungi organisasi dari gejolak, pencurian, perusakan dan kemalangan lainnya; membuat saran yang membangun; mengembangkan ketrampilan dan kemampuan; dan mengembangkan misi dalam komunitas yang lebih besar.

Selanjutnya Wagner \& Hollenbeck (2014) menyatakan perihal yang sama bahwa, OCB adalah tindakan yang mendorong kepentingan organisasi, tetapi bukan bagian resmi dari persyaratan pekerjaan setiap orang. Perilaku bebas (sukarela) bukanlah sebuah perilaku yang dituntut dalam melakukannya atau yang ditentukan dalam deskripsi kerja, tetapi merupakan sebuah rasa tanggung jawab dari karyawan terhadap organisasi, perilaku ini juga merupakan salah satu pilihan pribadi yang muncul dari dalam diri seseorang. Schermerhorn Jr, Hunt \& Osborn (2016) dan kawan-kawan mendefinisikan, OCB adalah sesuatu yang orang-orang lakukan untuk bekerja ekstra dalam pekerjaan mereka. Perilaku ini (extra-role) muncul karena perasaan sebagai anggota organisasi dan merasa puas apabila dapat melakukan suatu yang lebih kepada organisasi. Perasaan sebagai anggota dan puas bila melakukan suatu yang lebih hanya terjadi jika seseorang memiliki persepsi yang positif terhadap organisasinya.

Selanjutnya George dkk. (2005) menjelaskan OCB sebagai perilaku yang melebihi panggilan tugas dimana merupakan perilaku yang tidak ditentukan oleh anggota organisasi tetapi meskipun demikian penting bagi kelangsungan hidup dan efektifitas organisasi. Lebih lanjut Colquitt, Lepine \& Wesson (2015:43-44) mendefinisikan, OCB adalah sebagai perilaku sukarela karyawan yang mungkin atau pun tidak dihargai tetapi memberikan kontribusi kepada organisasi dengan meningkatkan kualitas dalam pekerjaan yang terjadi. Robbins \& Coulter (2018) menjelaskan OCB merupakan perilaku sukarela di luar aturan formal kerja. Dan akan menghasilkan fungsi afektif sebuah organisasi.

Dari beberapa deskripsi konsep di atas maka dapat disintesiskan OCB adalah perilaku yang bersifat sukarela, bukan merupakan tindakan yang terpaksa terhadap hal-hal yang mengedepankan kepentingan organisasi, perilaku individu sebagai wujud dari kepuasan berdasarkan kinerja, dan tidak diperintah secara formal, tidak berkaitan langsung dengan sistem reward.

\section{Locus of Control (LOC)}

Robbins \& Coulter (2018) menjelaskan bahwa, LOC adalah tingkat kepercayaan seseorang bahwa mereka bisa mengendalikan nasib mereka sendiri. Orang dengan LOC internal percaya mereka mengendalikan nasib mereka sendiri. Mereka lebih 
mungkin untuk mengambil tanggung jawab atas konsekuensi dan bergantung pada standar sendiri tehadap hal yang baik dan yang salah untuk panduan perilaku mereka. Mereka juga lebih cenderung menjadi konsisten dalam penilaian moral dan tindakan mereka. Orang dengan LOC eksternal percaya apa yang terjadi kepada mereka karena keberuntungan atau kesempatan. Mereka lebih kecil kemungkinannya untuk mengambil tanggung jawab pribadi untuk konsekuensi dari perilaku mereka dan lebih cenderung mengandalkan kekuatan-kekuatan eksternal.

Selanjutnya Gibson, Ivancevich, Donnelly \& Konopaske (1991) bahwa LOC adalah karakteristik kepribadian yang menggambarkan bahwa seseorang yang memandang kontrol hidup mereka datang dari dalam diri mereka maka yang demikian itu disebut sebagai LOC internal. Sedangkan orang yang yang percaya bahwa hidup mereka dikendalikan oleh faktor eksternal maka yang seperti itu disebut sebagai LOC eksternal. Slocum \& Hellriegel (2009) menjelaskan bahwa, LOC adalah sejauh mana orang percaya bahwa mereka bisa mengendalikan peristiwa yang mempengaruhi diri mereka. Individu yang memiliki internal LOC yang tinggi (internal) percaya bahwa perilaku mereka sendiri dan tindakan mereka sendiri yang lebih utama, tetapi tidak seluruhnya benar-benar menentukan banyak peristiwa dalam hidup mereka. Di sisi lain, individu yang memiliki LOC eksternal (external) percaya bahwa kesempatan, nasib, semuanya di tentukan secara signifikan di tentukan oleh pihak luar.

Eder \& Eisenberger (2007) menjelaskan bahwa POS dapat dipengaruhi oleh berbagai macam aspek mengenai perlakuan organisasi terhadap karyawannya dan selanjutnya akan mempengaruhi interpretasi karyawan terhadap perlakuan organisasi tersebut. LOC merupakan salah satu dari atribut personality yang dapat mempengaruhi OCB.

\section{Perceived Organizational Support (POS)}

Persepsi tentang dukungan organisasi atau POS mengacu pada definisi menurut Eisenberger, Huntington, Hutchison \& Sowa (1986:501) bahwa, POS merupakan keyakinan karyawan mengenai berapa besar organisasi peduli, menghargai kontribusi serta memperhatikan kesejahteraannya.

Menurut Aselage \& Eisenberger (2003:493) menjelaskan bahwa persepsi tentang dukungan organisasi adalah kepercayaan secara umum dari karyawan bahwa organisasi menghargai kontribusi dan peduli akan kesejahteraan mereka hal ini menunjukan komitmen organisasi terhadap karyawannya dan hal tersebut akan sangat menguntungkan. Noruzy, Shatery, Rezazadeh \& Hatami-Shirkouhi (2011:842) menjelaskan, Persepsi tentang dukungan organisasi adalah komitmen organisasi terhadap gurunya.

Jika guru yang merasa bahwa dirinya mendapatkan dukungan dari organisasi akan memiliki rasa kebermaknaan dalam diri guru tersebut. Hal inilah yang akan meningkatkan komitmen pada diri guru. Komitmen inilah yang pada akhirnya akan mendorong guru untuk berusaha membantu organisasi mencapai tujuannya, dan meningkatkan harapan bahwa performa kerja akan diperhatikan dan dihargai oleh organisasi.

Moorman, Blakely \& Niehoff (1998) menjelaskan bahwa, Persepsi tentang dukungan organisasi merupakan persepsi secara umum karyawan mengenai seberapa besar organisasi menghargai seluruh kontribusi karyawan dan peduli 
terhadap kesejahteraan karyawan. Lebih lanjut, Eisenberger, Stinglhamber, Vandenberghe, Sucharski \& Rhoades (2002:698) menjelaskan, Persepsi tentang dukungan organisasi juga dinilai sebagai jaminan bahwa bantuan akan tersedia dari organisasi ketika dibutuhkan untuk melaksanakan pekerjaan seseorang secara efektif dan untuk menghadapi situasi stress.

Ali, Rizavi, Ahmed \& Rasheed (2018:68-69) menemukan bahwa dukungan organisasi merupakan prediktor utama terhadap sikap, persepsi dan tindakan karyawan. Persepsi atas kesejahteraan karyawan yang dirasakan menjadi sebuah prediktor persepsi tentang dukungan organisasi, yang pada ahirnya dapat mempengaruhi tingginya keterikatan kerja dan OCB. Peneliti lain menemukan bahwa persepsi tentang dukungan organisasi tidak selamanya mampu menciptakan OCB, Devimageshkumar (2016:200) menemukan bahwa terdapat pengaruh yang lemah dan tidak konsisten antara persepsi tentang dukungan organisasi terhadap OCB. Hal ini terjadi karena persepsi dan komitmen karyawan terhadap organisasinya berbeda-beda, penilaian dan kepercayaan mereka terhadap organisasi tidak saling berkaitan).

Khan \& Ghufran (2018:3) menemukan bahwa persepsi tentang dukungan organisasi tidak memiliki pengaruh positif terhadap OCB, hal ini terjadi karena adanya karyawan yang lebih mementingkan kepentingan pribadi, promosi, dan insentif, jika pegawai tidak menperoleh insentif maka karyawan tersebut tidak merasa puas dengan pimpinannya dan merasa tidak diperhatikan kesejahteraannya maka kinerjanya akan buruk. Dengan kata lain ketika kinerjanya buruk maka perilaku sukarela tidak akan terjadi.

\section{METODE PENELITIAN}

Penelitian ini dilaksanakan di Sukabumi yang meliputi 4 SMA Negeri yang ada di kota Sukabumi. Sampel yang digunakan adalah simple random sampling dengan jumlah 70 guru. Metode yang digunakan dalam penelitian ini adalah metode survey dengan menggunakan kuesioner sebagai alat pengumpulan data pokok dan dokumentasi.

Penelitian ini menggunakan analisis jalur (path analysis) untuk mengetahui adanya pengaruh antar variabel sesuai dengan model kausal yang terbentuk. Sebelum kuesioner digunakan dalam penelitian ini terlebih dahulu dilakukan ujicoba untuk menentukan validitas dan reliabilitas instrumen. Hasil tersebut digunakan sebagai instrumen untuk mengambil data penelitian di lapangan. Analisis data meliputi: (1) deskripsi data, (2) uji prasyarat analisis normalitas, (3) analisis jalur yang meliputi: analisis model, pengujian hipotesis dan penentuan tingkat pengaruh.

\section{HASIL DAN PEMBAHASAN}

\section{Pengaruh Langsung LOC terhadap OCB}

Dari hasil perhitungan analisis jalur, pengaruh langsung LOC terhadap OCB guru SMA Negeri di Kota Sukabumi. Dari hasil perhitungan diperoleh nilai koefisien korelasi $r_{13}=0,382$ dan koefisien jalur $p_{31}=0,259$ dan dimana nilai koefisisen $t_{\text {hitung }}$ sebesar 2,560. Nilai koefisien $t_{\text {tabel }}$ untuk $\alpha=0.05$ sebesar 2,03. Hasil penelitian ini sesuai dengan peneltian O'Brien (2004:25) dalam Disertasinya: "Stated that a more internal LOC would relate to increased reporting of $\mathrm{OCB}$ and decreased 
reporting of $C W B$, were tested with correlations between LOC and voluntary behaviors. Moderate significant correlations were found in the expected directions. Specifically, LOC was positively correlated with OCB ( $r=0,40$, $p<0,001)$ and negatively correlated with CWB $(r=-0,24, p<0,01)$, supporting the hypotheses". Dengan demikian hipotesis 1 yang menduga terdapat pengaruh langsung LOC) terhadap OCB guru dapat diterima. Hal ini mencerminkan bahwa semakin positif LOC guru maka semakin tinggi OCB guru.

\section{Pengaruh Langsung POS terhadap OCB}

Dari hasil perhitungan analisis jalur, pengaruh langsung POS terhadap OCB guru SMA Negeri di Kota Sukabumi. Dari hasil perhitungan diperoleh nilai koefisien korelasi $r_{23}=0,434$ dan nilai koefisien jalur $p_{32}=0,340$ dimana nilai koefisisen $t_{\text {hitung }}$ sebesar 2,560. Nilai koefisien $t_{\text {tabel }}$ untuk $\alpha=0,05$ sebesar 2,03. Hasil penelitian ini sesuai dengan penelitian Noruzy dkk. (2011:845): "With respect to the predicted paths, our hypotheses were generally supported. OCB was significantly and positively predicted by Organizational Justice $(\beta=0,22)$, and $\operatorname{POS}(\beta=0,26)$. This set of predictors accounted for a combined $11 \%$ of the variance in organization performance. As hypothesized, Organizational Justice exerted a direct effect on the POS $(\beta=0,46)$. organizational Justice also effected indirectly OCB $(\beta=0,12)$ through POS. Thus aone can say that POS have meditational role between organizational justice and OCB”. Selanjutnya Thompson, Bergeron \& Bolino (2020) dalam penelitiannya menjelaskan, POS elicits felt obligation on the part of employees who, in turn, reciprocate by helping the organization through the performance of OCB. Dengan demikian hipotesis 2 yang menduga terdapat pengaruh langsung POS terhadap OCB guru dapat diterima. Hal ini mencerminkan bahwa semakin tinggi POS guru maka semakin tinggi OCB guru.

\section{Pengaruh langsung LOC terhadap POS}

Dari hasil perhitungan analisis jalur, pengaruh langsung LOC terhadap POS guru SMA Negeri di Kota Sukabumi. Dari hasil perhitungan diperoleh nilai koefisien korelasi $r_{12}=0,361$ dan nilai koefisien jalur $p_{21}=0,361$ dimana nilai koefisisen $t_{\text {hitung }}$ sebesar 2,560. Nilai koefisien $t_{\text {tabel }}$ untuk $\alpha=0.05$ sebesar 2,03. Hasil penelitian ini sesuai dengan pendapat Eisenberger dkk. (1986:501), "POS would be influenced by various aspects of an employee's treatment by the organization and would, in turn, influence the employee's interpretation of organizational motives underlying that treatment. and that "positive discretionary actions by the organization that benefited the employee would be taken as evidence that the organization cared about one's well-being and therefore could be counted on for subsequent rewards". Dengan demikian hipotesis 3 yang menduga terdapat pengaruh langsung LOC terhadap POS dapat diterima. Hal ini mencerminkan bahwa semakin tinggi LOC guru maka semakin tinggi POS guru.

Berdasarkan hasil penelitian, diusulkan beberapa rekomendasi untuk upaya yang dapat dilaksanakan dalam rangka meningkatkan perilaku extra-role atau OCB guru di Kotamadya Sukabumi sebagai berikut: (1) Hendaknya guru bisa meningkatkan keyakinan tentang kemampuan diri, kemandirian guru ditingkatkan dan rasa tanggungjawab guru juga ditingkatkan, karena LOC merupakan kendali 
individu atas pekerjaan guru dan kepercayaan terhadap keberhasilan diri, dan keyakinan guru bahwa mereka bertanggung jawab atas perilaku kerja dalam organisasi sekolah, karena LOC merupakan gambaran dari atribut tanggungjawab secara personal untuk menghasilkan yang lebih baik, baik untuk diri guru maupun untuk lingkungan organisasi sekolah. Karena LOC merupakan salah satu dari atribut personality yang dapat mempengaruhi OCB. (2) Untuk meningkatkan POS pada guru diantaranya adalah organisasi senantiasa menghargai kontribusi guru dan peduli akan kesejahteraan guru karena hal ini merupakan komitmen organisasi terhadap bawahannya dan hal tersebut akan sangat menguntungkan, Jika guru menganggap bahwa dukungan organisasi yang di terimanya tinggi, maka guru tersebut akan menyatukan keanggotaan sebagai anggota organisasi ke dalam identitas diri mereka dan kemudian mengembangkan hubungan dan persepsi yang lebih positif terhadap organisasi tersebut. Dan menurut berbagai meta analisis menjelaskan bahwa POS mempunyai pengaruh yang sangat tinggi terhadap perilaku In-role dan perilaku extra-role (OCB). Persepsi guru yang baik terhadap dukungan organisasional POS kepada kualitas kehidupan kerja mereka akan menimbulkan rasa "hutang budi" dalam diri mereka pada organisasi sehingga mereka akan merasa memiliki kewajiban untuk membayarnya. Kualitas interaksi atasan-bawahan juga diyakini sebagai prediktor OCB. (3) Para peneliti terkait dengan hasil penelitian ini, agar melibatkan lebih banyak variabel prediktor yang diduga berkorelasi positif dengan OCB guru. Selain itu selayaknya peneliti berikutnya dapat menggunakan juga sampel penelitian dari pimpinan sekolah dan instansi terkait.

\section{KESIMPULAN}

(1) terdapat pengaruh positif LOC terhadap OCB guru, yang ditentukan oleh derajat kekuatan pengaruh dalam bentuk koefisien korelasi dan koefisien jalur. Nilai koefisien jalur ini menentukan seberapa besar varians OCB guru ditentukan oleh variabel LOC. Selanjutnya dapat diketahui signifikansi pengaruh antara LOC terhadap OCB secara parsial. Hal ini mempunyai makna dan penegasan bahwa LOC secara empiris bukan satu-satunya variabel prediktor bagi varians skor OCB guru. (2) terdapat pengaruh positif POS terhadap OCB guru, yang ditentukan oleh derajat kekuatan pengaruh dalam bentuk koefisien korelasi dan koefisien jalur. Nilai koefisien jalur ini menentukan seberapa besar varians OCB guru ditentukan oleh variabel POS. Selanjutnya dapat diketahui kekuatan signifikansi pengaruh POS terhadap OCB guru secara parsial. Hal ini mempunyai makna dan penegasan bahwa POS secara empiris bukan satu-satunya variabel prediktor bagi varians skor OCB guru. (3) terdapat pengaruh positif LOC terhadap POS guru, ditentukan oleh derajat kekuatan pengaruh dalam bentuk koefisien korelasi dan koefisien jalur. Nilai koefisien jalur ini menentukan seberapa besar varians POS guru ditentukan oleh variabel LOC. selanjutnya dapat diketahui signifikansi pengaruh antara LOC dengan POS guru.

\section{REFERENSI}

Ali, F. H., Rizavi, S. S., Ahmed, I., \& Rasheed, M. (2018). Effects of perceived organizational support on organizational citizenship behavior-Sequential 
mediation by well-being and work engagement. Journal of the Punjab University Historical Society, 31(1), 111-131.

Aselage, J., \& Eisenberger, R. (2003). Perceived organizational support and psychological contracts: A theoretical integration. Journal of Organizational Behavior: The International Journal of Industrial, Occupational and Organizational Psychology and Behavior, 24(5), 491-509.

Colquitt, J., Lepine, J. A., \& Wesson, M. J. (2014). Organizational Behavior: Improving Performance and Commitment in the Workplace (4e). New York, NY, USA: McGraw-Hill.

DeviMageshkumar, S. (2016). Influence of Perceived Organizational Support, Organizational Commitment on Organizational Citizenship Behavior among Marketing Executives. The International Journal of Indian Psychology, 4(1), 194-201.

Eder, P., \& Eisenberger, R. (2007). Perceived Organizational Support: Reducing the Negative Influence of Coworker Withdrawal Behavior. Journal of Management, 34(1), 55-68.

Eisenberger, R., Huntington, R., Hutchison, S., \& Sowa, D. (1986). Perceived Organizational Support. Journal of Applied psychology, 71(3), 500-507.

Eisenberger, R., Stinglhamber, F., Vandenberghe, C., Sucharski, I. L., \& Rhoades, L. (2002). Perceived Supervisor Support: Contributions to Perceived Organizational Support and Employee Retention. 87(3), 565-573.

Finch, C. R., \& Crunkilton, J. R. (1999). Curriculum Development in Vocational and Technical Education. Planning, Content, and Implementation. Needham Heights, MA: Allyn and Bacon.

George, J. M., Jones, G. R., \& Sharbrough, W. C. (2005). Understanding and Managing Organizational Behavior. Upper Saddle River, NJ: Pearson Prentice Hall.

Gibson, J. L., Ivancevich, J. M., Donnelly, J. H., \& Konopaske, R. (1991). Organizations: Behavior, Structure, Processes. Homewood, IL: Irwin.

Khan, R. U., \& Ghufran, H. (2018). The Mediating Role of Perceived Organizational Support between Qualitative Job Insecurity, Organizational Citizenship Behavior and Job Performance. Journal of Entrepreneurship \& Organization Management, 7(1), 1000228.

Kunandar. (2007). Guru Profesional Implementasi Kurikulim Tingkat Satuan Pendidikan (KTSP) dan Sukses dalam Sertifikasi Guru. Depok: Rajagrafindo Persada.

Moorman, R. H., Blakely, G. L., \& Niehoff, B. P. (1998). Does perceived organizational support mediate the relationship between procedural justice and organizational citizenship behavior?. Academy of Management journal, 41(3), 351-357.

Noruzy, A., Shatery, K., Rezazadeh, A., \& Hatami-Shirkouhi, L. (2011). Investigation the relationship between organizational justice, and organizational citizenship behavior: The mediating role of perceived organizational support. Indian Journal of science and Technology, 4(7), 842847.

O‘Brien, K. E. (2004). Self-Determination Theory and Locus of Control as Antecedents of Voluntary Workplace Behaviors (Doctoral dissertation, University of South Florida). 
Robbins, S. P., \& Coulter, M. A. (2018). Management. Upper Saddle River, New Jersey: Pearson Education Inc.

Schermerhorn Jr, J. R., Hunt, J. G., \& Osborn, R. N. (2016). Organizational Behavior. New Jersey: John Wiley \& Sons

Slocum, J. W., \& Hellriegel, D. (2009). Principles of organizational behavior. Mason, OH: South-Western Cengage Learning.

Thompson, P. S., Bergeron, D. M., \& Bolino, M. C. (2020). No obligation? How gender influences the relationship between perceived organizational support and organizational citizenship behavior. Journal of Applied Psychology, 105(11), 1338-1350.

Usman, H. (2012). Manajemen Teori Praktik dan Riset Pendidikan. Jakarta: Bumi Aksara.

Wagner, J. A., \& Hollenbeck, J. R. (2014). Organizational behavior: Securing competitive advantage. New York: Routledge. 